\title{
Inhibition of duck hepatitis B virus replication by mimic peptides in vitro
}

\author{
HONGYU JIA ${ }^{1 *}$, CHANGHONG LIU $^{2 *}$, YING YANG $^{1 *}$, HAIHONG ZHU $^{1}$, \\ FENG CHEN $^{1}$, JIHONG LIU ${ }^{3}$ and LINFU ZHOU ${ }^{4}$
}

\begin{abstract}
${ }^{1}$ State Key Laboratory for Diagnosis and Treatment of Infectious Diseases, Collaborative Innovation Center for Diagnosis and Treatment of Infectious Diseases, The First Affiliated Hospital, School of Medicine, Zhejiang University, Hangzhou, Zhejiang 310003; ${ }^{2}$ Department of Gastroenterology, Shandong Provincial Qianfoshan Hospital, Jinan, Shandong 250013;

${ }^{3}$ Department of Medical Oncology, The First People's Hospital of Hangzhou, Hangzhou, Zhejiang 310009;

${ }^{4}$ Department of Molecular Biology, Zhejiang University School of Medicine, Hangzhou, Zhejiang 310038, P.R. China
\end{abstract}

Received September 16, 2014; Accepted July 10, 2015

DOI: $10.3892 /$ etm.2015.2757

\begin{abstract}
The aim of the present study was to investigate the inhibitory effect of specific mimic peptides targeting duck hepatitis B virus polymerase (DHBVP) on duck hepatitis B virus (DHBV) replication in primary duck hepatocytes. Phage display technology (PDT) was used to screen for mimic peptides specifically targeting DHBVP and the associated coding sequences were determined using DNA sequencing. The selected mimic peptides were then used to treat primary duck hepatocytes infected with DHBV in vitro. Infected hepatocytes expressing the mimic peptides intracellularly were also prepared. The cells were divided into mimic peptide groups (EXP groups), an entecavir-treated group (positive control) and a negative control group. The medium was changed every $48 \mathrm{~h}$. Following a 10-day incubation, the cell supernatants were collected. DHBV-DNA in the cellular nucleus, cytoplasm and culture supernatant was analyzed by quantitative polymerase chain reaction (qPCR). Eight mimic peptides were selected following three PDT screening rounds for investigation in the DHBV-infected primary duck hepatocytes. The qPCR results showed that following direct treatment with mimic peptide 2 or 7, intracellular expression of mimic peptide 2 or 7, or treatment with entecavir, the DHBV-DNA levels in the culture supernatant and cytoplasm of duck hepatocytes
\end{abstract}

Correspondence to: Professor Linfu Zhou, Department of Molecular Biology, Zhejiang University School of Medicine, 388 Yuhangtang Road, Hangzhou, Zhejiang 310038, P.R. China E-mail: zhoulinfu73@163.com

*Contributed equally

Abbreviations: DHBV, duck hepatitis B virus; DHBVP, duck hepatitis B virus polymerase; PDT, phage display technology; HBV, hepatitis $\mathrm{B}$ virus

Key words: duck hepatitis B virus, polymerase, phage display technology, mimic peptides, primary duck hepatocytes were significantly lower than those in the negative control $(\mathrm{P}<0.05)$. The cytoplasmic DHBV-DNA content of the cells treated with mimic peptide 7 was lower than that in the other groups $(\mathrm{P}<0.05)$. In addition, the DHBV-DNA content of the nuclear fractions following the intracellular expression of mimic peptide 7 was significantly lower than that in the other groups $(\mathrm{P}<0.05)$. Mimic peptides specifically targeting DHBVP, administered directly or expressed intracellularly, can significantly inhibit DHBV replication in vitro.

\section{Introduction}

Chronic hepatitis B (CHB) is caused by infection by the hepatitis B virus (HBV) (1-3). HBV belongs to the Hepadnaviridae family of viruses. Currently, the Hepadnaviridae family is known to include HBV, woodchuck hepatitis virus (WHV), ground squirrel hepatitis virus, heron hepatitis B virus and duck hepatitis B virus (DHBV) (4). All virus types within the Hepadnaviridae family are tiny and exhibit hepatotropism. Hepadnaviruses are a type of DNA virus, with similar viron shape and genome and replicate via RNA reverse transcription (5). The discovery of hepadnaviruses in mammals and birds provided the experimental and ethical basis on the study of HBV biological mechanisms $(6,7)$. In a previous study of human HBV infection mechanisms, marmots infected with WHV (8) and the ducks infected with DHBV are the most widely used model (9-11). Due to the similarity between HBV-infected humans and DHBV-infected duck, ducks infected with DHBV are an effective model for the study of hepadnaviruses. Super spiral of covalently closed circular DNA molecules (cccDNA) are viral genome replication intermediates in the hepatocyte nuclei, and the key factor underlying persistent Hepadnaviridae infection (12-14). Currently, no methods are available for the complete inhibition of their formation. The approved drugs for the treatment of CHB, which are nucleotide analogs and interferons, have certain disadvantages, such as a poor side-effect profile. The identification of novel anti-HBV drugs has become a key focus of research in the area of viral hepatitis (15-18). Duck hepatitis B virus polymerase (DHBVP) is essential for duck 
hepatitis B virus (DHBV) replication $(19,20)$; therefore, the functional blockade of DHBVP has the potential to inhibit HBV genome replication. In the present study, phage display technology (PDT) was used to screen for mimic peptides that specifically interact with DHBVP. The inhibitory effect of these mimic peptides on DHBV replication in primary duck hepatocytes was investigated in vitro in an effort to identify novel effective drugs against HBV infections.

\section{Materials and methods}

PDT screening test for mimic peptides specifically targeting DHBVP and the determination of the associated nucleotide sequences. Peptides targeting DHBVP functional sites were dissolved in dimethyl sulfoxide at a final concentration of $100 \mu \mathrm{g} / \mathrm{ml}$. These peptides were synthesized according to the DHBVP sequence of Shaoxing duck, which surrounding the YMDD sites. Each well of a 96-well ELISA plate (Greiner Bio-One, Frickenhausen, Germany) was coated with peptide solution and then treated with $150 \mu \mathrm{l}$ synthesized peptide $(1 \mathrm{mg} / \mathrm{ml})$ and incubated at $4^{\circ} \mathrm{C}$ overnight. Following blocking at $4^{\circ} \mathrm{C}$ for $\geq 1 \mathrm{~h}$, each ELISA plate was washed with Tris-buffered saline with Tween-20 (TBST; Promega Corporation, Madison, WI, USA) six times. A diluted phage peptide library (C7C Phage Display Peptide library; New England Biolabs, Beverly, MA, USA) was added and the plate was incubated at room temperature for $60 \mathrm{~min}$. Each plate was then washed with TBST 10 times and each well was eluted with $100 \mu \mathrm{l}$ acidic eluent (provided with the $\mathrm{C} 7 \mathrm{C}$ library) at room temperature for $\leq 10 \mathrm{~min}$. Eluents were collected in microcentrifuge tubes and neutralized with neutralizing solutions (provided with the $\mathrm{C} 7 \mathrm{C}$ library). Titers were determined using $1 \mu$ l eluents, while the remaining eluents were added to $20 \mathrm{ml}$ Escherichia (E.) coli ER2537 (New England Biolabs; early logarithmic phase) and incubated for $4.5 \mathrm{~h}$ at $37^{\circ} \mathrm{C}$. Samples were precipitated and purified for further screening, following the manufacturer instructions included with the experimental kit. Three rounds of the above-mentioned screening process were performed. Elutions from the third screening step were diluted and spotted into the plates. Clear phage plaques were removed for DNA extraction and, following DNA sequencing, the corresponding amino acid sequences were determined and used for the mimic peptide synthesis process. The selected mimic peptides were synthesized by Chinese Peptide Co. (Hangzhou, China).

Serum sample and hepatocyte preparation. Six randomly selected domestic male ducks (Shaoxing ducks; average age, 1 year; average weight, $1 \mathrm{~kg}$; Zhejiang Academy of Agricultural Sciences, Zhejiang, China) were prepared and $1 \mathrm{ml}$ serum from each duck was isolated for analysis. Primary duck hepatocytes were isolated from liver tissue as described previously (21). In brief, the liver was aseptically removed from each duck and washed twice with sterile saline solution. The livers were then cut into pieces and digested with trypsin in serum-free Dulbecco's modified Eagle's medium (DMEM; Gibco Life Technologies, Carlsbad, CA, USA) for $30 \mathrm{~min}$ at $37^{\circ} \mathrm{C}$. The resulting hepatocytes were collected by centrifugation at $1,600 \mathrm{x} \mathrm{g}$ for $12 \mathrm{~min}$ and then washed with sterile saline solution and culture medium twice. Cells were counted and seeded into $60-\mathrm{mm}$ dishes at a density of $2 \times 10^{6}$ per well.
The cells were cultured in a $5 \% \mathrm{CO}_{2}$ incubator at $37^{\circ} \mathrm{C}$. This study was carried out in strict accordance with the recommendations in the Guide for the Care and Use of Laboratory Animals of the National Institutes of Health (8th edition, 2011). The protocol was approved by the Committee on the Ethics of Animal Experiments of the First Affiliated Hospital, Zhejiang University School of Medicine (Hangzhou, China; Permit Number, 162). All surgery was performed under sodium pentobarbital anesthesia, and all efforts were made to minimize suffering.

Infection of hepatocytes with $D H B V$. Blood from DHBV-positive adult ducks was aseptically collected and incubated overnight at room temperature. The samples were centrifuged at 3,000 x $\mathrm{g}$ for $10 \mathrm{~min}$ to isolate the serum. Disposable filters were used to completely remove the bacteria. The infection of hepatocytes with the serum was then performed as follows (22): Primary duck hepatocytes were incubated for $18 \mathrm{~h}$ and then washed with DMEM containing $1 \%$ fetal bovine serum (FBS; Hyclone, Logan, UT, USA). Viral solution (30 $\mu \mathrm{l}$ duck serum; $5 \times 10^{9}$ virions $/ \mathrm{ml}$ ) was added to the cells, followed by $3 \mathrm{ml}$ serum-free DMEM, and the cells were then incubated.

Mimic peptide treatment of hepatocytes. Ten groups of infected hepatocytes were established, including eight synthetic mimic peptide groups [experimental (EXP) groups], an entecavir-treated group (positive control), and a phosphate-buffered saline (PBS)-treated group (negative control). In the EXP groups, $30 \mu \mathrm{l}(100 \mu \mathrm{mol})$ mimic peptide solution was added to each well, and $3 \mu \mathrm{l}(10 \mathrm{mmol})$ entecavir stock solution or $30 \mu \mathrm{l}$ PBS was added to the control groups, respectively. The cells were incubated at $37^{\circ} \mathrm{C}$ in a $5 \% \mathrm{CO}_{2}$ incubator and the medium was changed every $48 \mathrm{~h}$. Cell culture supernatants were collected and stored at $-20^{\circ} \mathrm{C}$ for future analysis. Following each change of medium, $30 \mu \mathrm{l}$ mimic peptide solution was again added to the wells of the EXP groups and $3 \mu \mathrm{l}$ entecavir stock solution or $30 \mu \mathrm{l}$ PBS was added to the control groups, respectively. After a 10-day incubation, the cell supernatants were collected and the cells were washed twice with PBS and digested with $0.25 \%$ trypsin. Following centrifugation at $1,500 \mathrm{x}$ g at $4^{\circ} \mathrm{C}$ for $5 \mathrm{~min}$ and washing twice with PBS, the cells in each well were collected and counted. Three replications were performed under each condition.

DHBV-DNA extraction and determination by quantitative polymerase chain reaction $(q P C R)$. The DHBV-DNA extraction of cell fractions was performed as described previously (23). Hepatocytes from the various treatment groups were washed twice with PBS and then $0.5 \mathrm{ml}$ TBS lysis buffer was added. Following centrifugation at $1,500 \mathrm{x} \mathrm{g}$ at $4^{\circ} \mathrm{C}$ for $5 \mathrm{~min}$, cell nuclear fractions were sedimented and separated from the cytoplasmic fractions in the supernatants. Nuclear fractions were washed twice with $0.5 \mathrm{ml}$ TBS and then dissolved in $1 \mathrm{ml}$ radio-immunoprecipitation assay (RIPA) solution. The cytoplasm fractions were mixed with equivalent volumes of RIPA solution. Equal volumes of lysis buffer were then added and the resulting mixtures were incubated at $55^{\circ} \mathrm{C}$ for $2 \mathrm{~h}$ to digest the proteins. Following 
Table I. Nucleotide sequences and amino acid sequences of the selected mimic peptides.

\begin{tabular}{llc} 
No. & Nucleotide sequences & Amino acid sequences \\
\hline 1 & ACCTCCACCTGTAAAGTCCTCTGATCCTGAGAGTGAGA & Gln-Asp-Gln-Arg-Thr-Phe-Thr \\
2 & ACCTCCACCAATCGGAGTATGAGAACCAGAGAGTGAGA & Leu-Val-Thr-His-Thr-Pro-Ile \\
3 & ACCTCCACCCCGAACAGCGTAGCAGGAACAGAGTGAGA & Val-Pro-Ala-Thr-Leu-Phe-Arg \\
4 & ACCTCCACCCCGCGGCGGATGAAGATGAGGAGAGTGAGA & Pro-His-Leu-His-Pro-Pro-Arg \\
5 & ACCTCCACCATGCGAATGATGTAGAGACATAGAGTGAGA & Met-Ser-Leu-His-His-Ser-His \\
6 & ACCTCCACCACTCGACGCAGTACGCAGAGCAGAGTGAGA & Ala-Leu-Arg-Thr-Ala-Ser-Ser \\
7 & ACCTCCACCATGACGCGGATAAATAGCATGAGAGTGAGA & His-Ala-Ile-Tyr-Pro-Arg-His \\
8 & ACCTCCACCAGTAGCAGTCGGAGGCGGCCTAGAGTGAGA & Arg-Pro-Pro-Pro-Thr-Ala-Thr
\end{tabular}

Italicized letters represent the code that differs between the 8 sequences presented, and is displayed as amino acids in the 'Amino acid sequences' column.

digestion, the samples were extracted with equal volumes of a phenol-chloroform-isoamyl alcohol (25:24:1) mixture and the DNA in the aqueous phase was sedimented with 2.5 volumes of alcohol and 1/10 volumes of $3 \mathrm{M}$ sodium acetate. The DNA was recovered following centrifugation at $12,000 \times \mathrm{g}$ at $4^{\circ} \mathrm{C}$ for $15 \mathrm{~min}$. Following washing with $70 \%$ alcohol, DNA was dissolved with Tris-ethylenediaminetetraacetic acid buffer and quantified using agarose gel and fluorescence, according to the manufacturer instructions of a QIAquick Gel Extraction Kit (Qiagen, Hilden, Germany).

The DHBV-DNA of the cell culture supernatant was extracted using the QIAamp MinElute Virus Spin kit (Qiagen) according to the manufacturer's instructions. The DNA samples were stored at $-20^{\circ} \mathrm{C}$ for future analysis.

The qPCR for DHBV-DNA was performed using SYBR-Green I (Bioasia Life Technology Co. Ltd., Shanghai, China) in a real-time PCR instrument (Mastercycler ${ }^{\circledR}$ ep realplex; Eppendorf, Hamburg, Germany; Registration ID 2273536). The PCR program was designed as follows: Pre-denaturation at $95^{\circ} \mathrm{C}$ for $5 \mathrm{~min}$ and 42 cycles including 15-sec denaturation at $94^{\circ} \mathrm{C}, 30-\mathrm{sec}$ annealing at $56^{\circ} \mathrm{C}$, and a 45 -sec extension at $72^{\circ} \mathrm{C}$. The DNA contents were measured at each cycle end and calculated using a standard curve.

Construction of mimic peptide-expressing recombinant plasmids. Purified DHBVP PCR products $(8 \mu \mathrm{l})$ were obtained using a QIAquick PCR Purification Kit (Qiagen), according to the manufacturer instructions. These products were thoroughly mixed with $1.5 \mu \mathrm{l} \mathrm{BamHI}, 1.5 \mu \mathrm{l}$ HindIII, $25 \mu 1$ sterile water and $4 \mu 110 \mathrm{X}$ buffer (Qiagen). The mixtures were incubated at $37^{\circ} \mathrm{C}$ for 1.5 h. Purified pGEM ${ }^{\circledR}(4 \mu \mathrm{l}$; Promega) was digested similarly. The products were purified using gel extraction methods and the DHBVP fragment was ligated into the pGEM vector using T4 DNA ligase. The ligation products were used to transform E. coli competent cells, and the positive clones were chosen for sequencing.

Measurement of the inhibitory effect on DHBV inhibition of mimic peptides expressed intracellularly. Plasmids expressing the mimic peptides were used to transfect duck primary hepatocytes pre-infected with DHBV. The DHBV-DNA contents of the cells were then determined. In the EXP groups, $1.2 \mu \mathrm{g}$ mimic peptide-expressing plasmid combined with $3 \mu \mathrm{l}$ liposomes were added to each well. In the control groups, $1.2 \mu \mathrm{g}$ pEGFP-N1 plasmid (Clontech Laboratories, Inc., Mountain View, CA, USA) combined with $3 \mu$ l liposomes were used. The medium was changed to serum-free DMEM following transfection and the cells were incubated at $37^{\circ} \mathrm{C}$ in a $5 \% \mathrm{CO}_{2}$ incubator. The medium was changed to DMEM containing 5\% FBS, $300 \mathrm{mg} / 1$ penicillin, $100 \mathrm{mg} / \mathrm{l}$ streptomycin, $1 \mathrm{mg} / \mathrm{l}$ insulin, $1.5 \mathrm{mg} / \mathrm{ml}$ glucose, $10 \mathrm{U} / \mathrm{ml}$ nystatin and $1 \times 10^{-5} \mathrm{M}$ hydrocortisone-hemisuccinate after 6-h incubation. Entecavir (3 $\mu \mathrm{l}$ ) was added to each well in the entecavir-treated group while $3 \mu$ l PBS was added to the wells of the negative control group. The medium was changed every $48 \mathrm{~h}$ and the collected cell supernatants were stored at $-20^{\circ} \mathrm{C}$ for future analysis. After 10 days of incubation, the cell supernatants were collected and the cells were washed twice with PBS and digested with $0.25 \%$ trypsin. Following centrifugation at $1,500 \mathrm{x}$ g at $4^{\circ} \mathrm{C}$ for 5 min and washing twice with PBS, the cells in each well were collected and counted. DHBV-DNA was then extracted as described previously.

Inhibition rate analysis. The DHBV-DNA inhibition rate of the mimic peptides was calculated as follows: Inhibition rate $(\%)=[$ (measured DNA content of the negative control - measured DNA content of the specific treatment group)/measured value of the negative control] $\mathrm{x} 100$.

Statistical analysis. The data were analyzed by SPSS 17.0 for Windows (SPSS Inc., Chicago, IL, USA). A homogeneity test of variance revealed unequal variances between groups, so a Kruskal-Wallis test was performed for further analysis. $\mathrm{P}<0.05$ was considered to indicate a statistically significant difference.

\section{Results}

Mimic peptides specifically targeting DHBVP and the associated nucleotide sequences. Three screening rounds were performed and the nucleotide sequences of eight mimic peptides were selected (Table I; the DNA content of another two mimic peptides were too weak to be detected). The amino acid sequences of the selected mimic peptides were deduced from the nucleotide sequences (Table I). The eight mimic 


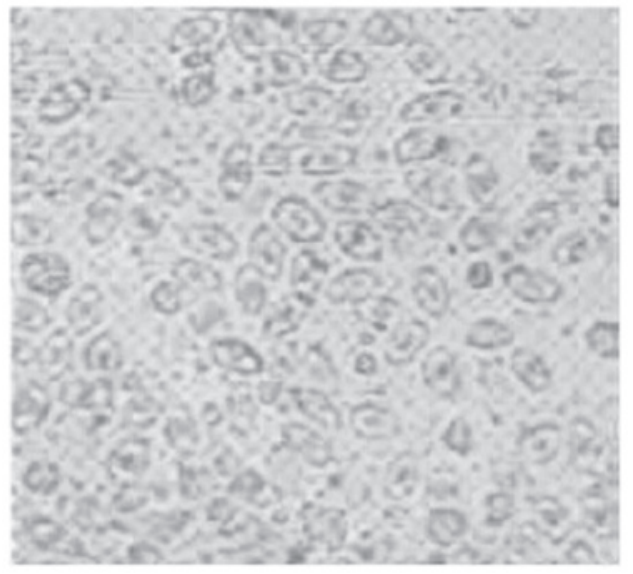

Figure 1. Freshly isolated primary duck hepatocytes (magnification, x100).

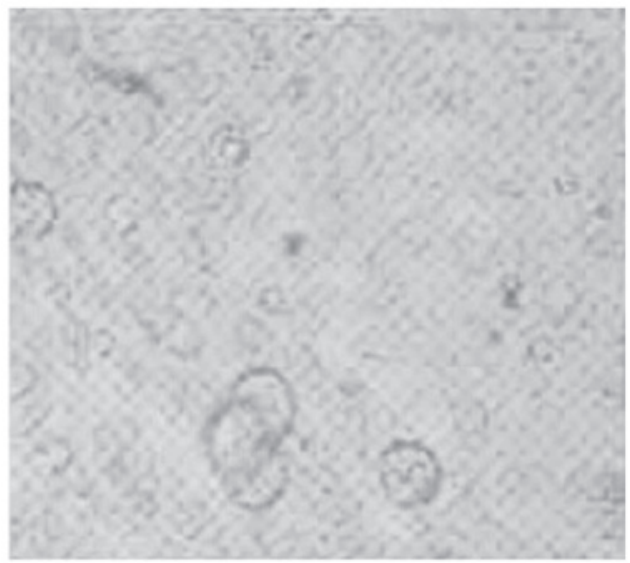

Figure 2. Duck primary hepatocytes $2 \mathrm{~h}$ after dissection (magnification, $\mathrm{x} 100)$.

peptides were synthesized according to the associated amino acid sequences.

DHBV infection of primary cultured cells. The primary duck hepatocytes were successfully isolated and attached in culture $12 \mathrm{~h}$ following their isolation. After culturing for 8 days, the proliferating hepatocytes covered the entire surface of the dish. No significant differences were observed between the EXP and control groups. Cell morphology at different time-points is shown in Figs. 1-4.

Inhibition of $D H B V-D N A$ by treatment with mimic peptides. The DHBV-DNA levels in the cell culture supernatants, cytoplasmic fractions and nuclear fractions are shown in Table II.

The DHBV-DNA levels of the cell culture supernatants and cytoplasm fractions in the EXP groups treated with mimic peptides 2 or 7 and the positive (entecavir) group were significantly decreased compared with those in the negative control group $(\mathrm{P}<0.05)$. In addition, there were no significant difference between the EXP groups treated with mimic peptides 2 or 7 and the positive control $(\mathrm{P}>0.05)$.

The DHBV-DNA inhibition rates in the cell culture supernatants for hepatocytes treated with mimic peptides 2 and 7 were 94.1 and $96.9 \%$, respectively, similar to the inhi-

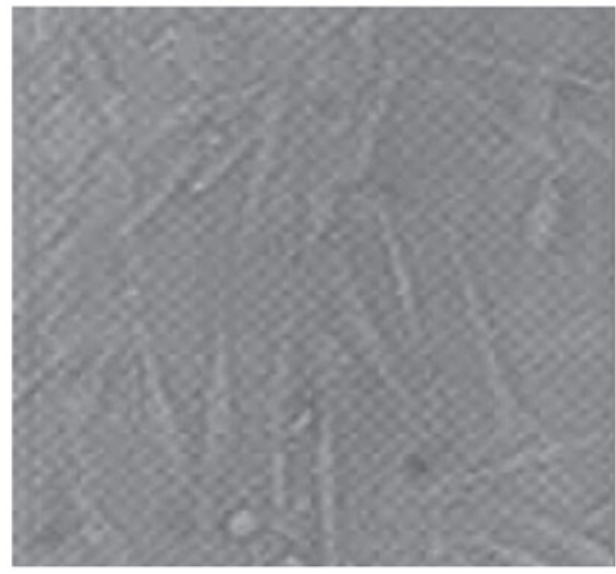

Figure 3. Duck primary hepatocytes at day 4 of culture (magnification, x100).

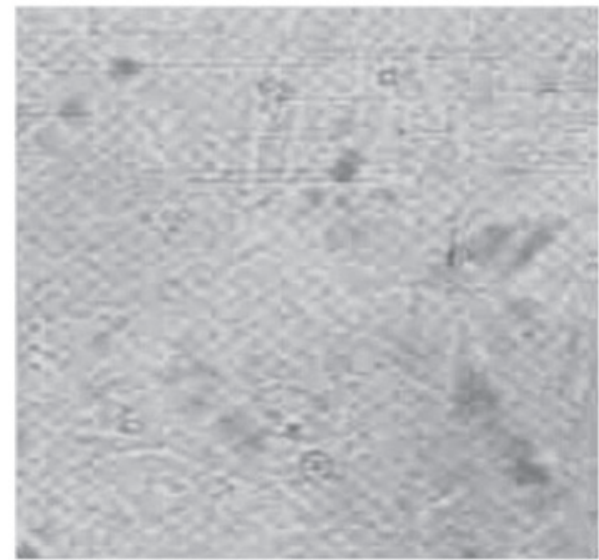

Figure 4. Duck primary hepatocytes following culturing for 8 days (magnification, $\mathrm{x} 100)$

bition ratio of $97.4 \%$ in the positive control $(\mathrm{P}>0.05)$. The DHBV-DNA inhibition rates in the cytoplasm fractions for mimic peptides 2 and 7 were 89.9 and $93.9 \%$, respectively, similar to the entecavir-mediated inhibition rate of $90.6 \%$ $(\mathrm{P}>0.05)$.

Inhibition of $\mathrm{DHBV}$-DNA by intracellularly expressed mimic peptides. The DHBV-DNA levels of the cell culture supernatants, cytoplasmic fractions and cell nuclear fractions from cells intracellularly expressing mimic peptides are shown in Table III.

The DHBV-DNA levels in the EXP groups intracellularly expressing mimic peptides 2 or 7 and the positive control group were significantly decreased compared with those in the negative control group $(\mathrm{P}<0.05)$. Furthermore, the DHBV-DNA levels of the nuclear fractions in the EXP group intracellularly expressing mimic peptide 7) were significantly decreased compared with those in the negative control group, and were the lowest among all the groups $(\mathrm{P}<0.05)$.

The inhibitory effect on DHBV-DNA levels in the cell culture supernatants was similar among the EXP groups treated with mimic peptides 2 or 7 and the positive control, and their respective inhibition rates were 95.0, 98.4 and 98.0\% ( $\mathrm{P}>0.05)$. The respective inhibition rates of the cytoplasmic DHBV-DNA 
Table II. DHBV-DNA levels of the cell culture supernatants, cytoplasmic fractions and nuclear fractions following treatment with mimic peptides targeting DHBV polymerase.

\begin{tabular}{lccc}
\hline No. & Cell culture supernatants & Cytoplasmic fractions & Nuclear fractions \\
\hline 1 & $1.73 \mathrm{E} 5 \pm 2.16 \mathrm{E} 5$ & $6.53 \mathrm{E} 5 \pm 6.37 \mathrm{E} 3$ & $1.34 \mathrm{E} 5 \pm 4.27 \mathrm{E} 4$ \\
2 & $5.68 \mathrm{E} 4 \pm 7.07 \mathrm{E} 5^{\mathrm{a}, \mathrm{b}}$ & $5.31 \mathrm{E} 4 \pm 1.59 \mathrm{E} 4^{\mathrm{a}, \mathrm{b}}$ & $4.14 \mathrm{E} 5 \pm 5.17 \mathrm{E} 4$ \\
3 & $6.31 \mathrm{E} 5 \pm 4.18 \mathrm{E} 4$ & $4.83 \mathrm{E} 5 \pm 3.53 \mathrm{E} 4$ & $6.32 \mathrm{E} 5 \pm 5.14 \mathrm{E} 3$ \\
4 & $1.14 \mathrm{E} 5 \pm 7.35 \mathrm{E} 3$ & $1.79 \mathrm{E} 5 \pm 2.13 \mathrm{E} 5$ & $7.15 \mathrm{E} 5 \pm 3.82 \mathrm{E} 4$ \\
5 & $1.48 \mathrm{E} 5 \pm 7.39 \mathrm{E} 4$ & $1.63 \mathrm{E} 5 \pm 6.45 \mathrm{E} 4$ & $4.79 \mathrm{E} 5 \pm 2.24 \mathrm{E} 4$ \\
6 & $2.65 \mathrm{E} 5 \pm 3.24 \mathrm{E} 4$ & $2.43 \mathrm{E} 5 \pm 2.74 \mathrm{E} 4$ & $6.37 \mathrm{E} 5 \pm 1.31 \mathrm{E} 4$ \\
7 & $2.99 \mathrm{E} 4 \pm 2.41 \mathrm{E} 4^{\mathrm{a}, \mathrm{b}}$ & $3.22 \mathrm{E} 4 \pm 5.23 \mathrm{E} 4^{\mathrm{a}, \mathrm{b}}$ & $3.41 \mathrm{E} 5 \pm 9.47 \mathrm{E} 4$ \\
8 & $6.37 \mathrm{E} 5 \pm 2.14 \mathrm{E} 4$ & $3.01 \mathrm{E} 5 \pm 5.38 \mathrm{E} 4$ & $4.49 \mathrm{E} 5 \pm 3.25 \mathrm{E} 4$ \\
Positive control & $2.47 \mathrm{E} 4 \pm 3.39 \mathrm{E} 4^{\mathrm{a}}$ & $4.94 \mathrm{E} 4 \pm 1.47 \mathrm{E} 3$ & $5.72 \mathrm{E} 5 \pm 1.56 \mathrm{E} 4$ \\
Negative control & $9.63 \mathrm{E} 5 \pm 1.59 \mathrm{E} 5$ & $5.25 \mathrm{E} 5 \pm 1.59 \mathrm{E} 5$ & $7.74 \mathrm{E} 5 \pm 1.63 \mathrm{E} 4$ \\
\hline
\end{tabular}

${ }^{\mathrm{a}} \mathrm{P}<0.05$ compared with the negative control; ${ }^{\mathrm{b}} \mathrm{P}>0.05$ compared with the positive (entecavir-treated) control. DHBV-DNA duck hepatitis $\mathrm{B}$ virus-DNA.

Table III. DHBV-DNA contents of the cell culture supernatants, cytoplasmic fractions and nuclear fractions following cellular expression of mimic peptides.

\begin{tabular}{lccc}
\hline No. & Culture supernatants & Cytoplasmic fractions & Nuclear fractions \\
\hline 1 & $1.80 \mathrm{E} 5 \pm 3.86 \mathrm{E} 4$ & $2.01 \mathrm{E} 5 \pm 3.40 \mathrm{E} 4$ & $1.67 \mathrm{E} 5 \pm 2.66 \mathrm{E} 4$ \\
2 & $3.51 \mathrm{E} 4 \pm 1.51 \mathrm{E} 4^{\mathrm{a}, \mathrm{b}}$ & $7.09 \mathrm{E} 4 \pm 5.91 \mathrm{E} 3^{\mathrm{a}, \mathrm{b}}$ & $3.89 \mathrm{E} 5 \pm 4.66 \mathrm{E} 4$ \\
3 & $1.96 \mathrm{E} 5 \pm 3.30 \mathrm{E} 4$ & $2.56 \mathrm{E} 5 \pm 3.74 \mathrm{E} 5$ & $4.02 \mathrm{E} 5 \pm 2.08 \mathrm{E} 4$ \\
4 & $1.94 \mathrm{E} 5 \pm 3.45 \mathrm{E} 4$ & $2.48 \mathrm{E} 5 \pm 3.53 \mathrm{E} 4$ & $2.05 \mathrm{E} 5 \pm 7.09 \mathrm{E} 4$ \\
5 & $1.85 \mathrm{E} 5 \pm 3.44 \mathrm{E} 4$ & $2.07 \mathrm{E} 5 \pm 4.10 \mathrm{E} 4$ & $2.01 \mathrm{E} 5 \pm 6.25 \mathrm{E} 4$ \\
6 & $2.22 \mathrm{E} 5 \pm 1.20 \mathrm{E} 4$ & $4.01 \mathrm{E} 5 \pm 4.48 \mathrm{E} 4$ & $2.82 \mathrm{E} 5 \pm 6.09 \mathrm{E} 4$ \\
7 & $1.14 \mathrm{E} 4 \pm 8.68 \mathrm{E} 3^{\mathrm{a}, \mathrm{b}}$ & $8.50 \mathrm{E} 4 \pm 5.94 \mathrm{E} 4^{\mathrm{a}, \mathrm{b}}$ & $9.83 \mathrm{E} 4 \pm 6.02 \mathrm{E} 3^{\mathrm{a}}$ \\
8 & $4.74 \mathrm{E} 5 \pm 3.84 \mathrm{E} 4$ & $2.35 \mathrm{E} 5 \pm 4.63 \mathrm{E} 4$ & $2.37 \mathrm{E} 5 \pm 6.17 \mathrm{E} 4$ \\
Positive control & $1.40 \mathrm{E} 4 \pm 1.18 \mathrm{E} 4^{\mathrm{a}}$ & $8.79 \mathrm{E} 4 \pm 8.38 \mathrm{E} 3^{\mathrm{a}}$ & $4.37 \mathrm{E} 5 \pm 2.55 \mathrm{E} 4$ \\
Negative control & $7.09 \mathrm{E} 5 \pm 6.15 \mathrm{E} 4$ & $5.14 \mathrm{E} 5 \pm 7.95 \mathrm{E} 4$ & $6.94 \mathrm{E} 5 \pm 1.53 \mathrm{E} 4$
\end{tabular}

${ }^{\mathrm{a}} \mathrm{P}<0.05$ compared with the negative control; ${ }^{\mathrm{b}} \mathrm{P}>0.05$ compared with the positive (entecavir-treated) control. DHBV-DNA, duck hepatitis B virus-DNA.

levels in the EXP groups treated with mimic peptides 2 or 7 and the positive control were 86.2, 83.5 and $82.9 \%(\mathrm{P}>0.05)$. The EXP group treated with mimic peptide no 7 , however, had a much lower DHBV-DNA level in the nuclear fractions than did the positive control, and their respective inhibition rates were 85.8 and $37.0 \%(\mathrm{P}<0.05)$.

\section{Discussion}

Chronic HBV infection is a devastating health problem that is closely associated with different stages of liver injury, hepatic fibrosis and hepatocellular carcinoma (24-26). As such, the development of an effective HBV treatment is a major task in the medical field (27). HBV is a member of Orthohepadnavirus belonging to the family Hepadnaviridae. The Avihepadnavirus genus, which includes DHBV and can infect bird species, also belongs to the same family $(28,29)$. Viruses of this family are quite small and show hepatotropic characteristics. These viruses are DNA viruses with similar virion morphology/genomes that replicate through RNA reverse transcription. DHBV contains a relaxed circular partially double-stranded DNA (rcDNA) genome that is 3,021 or 2,027 bp long. A minus-strand nick exists in DHBV rcDNA, whereas the plus-strand of DHBV rcDNA remains intact $(30,31)$. DHBVP contains 788 amino acids, weighs $\sim 89 \mathrm{kD}$ and is composed of four functional domains starting from the terminal protein domain in the $\mathrm{N}$ terminus, spacer domain, reverse transcriptase domain, and $\mathrm{RNaseH}$ domain in the $\mathrm{C}$ terminus (32). Since viral polymerase is essential for the biological cycle of Hepadnaviridae, anti-HBV drugs in development mainly focus on viral polymerase (33). In the present study, peptides surrounding the YMDD site, which is targeted by nucleotide analogs (34), were selected as DHBV drug-screening targets. Current DHBV drug development is mainly focused on nucleotide analogs, although the clinical applications of nucleotide analogs have been limited 
by problems such as long research and development cycles, high toxicity, single target sites and acquired drug resistance $(35,36)$.

PDT is a novel technique in which foreign proteins or peptides are fused with phage coat proteins at the phage surface while maintaining specific spatial conformations. It enables the screening of proteins and peptides via specific affinity. PDT is an efficient screening technique for biological macromolecules, which combines physically linked genotypes and phenotypes to identify proteins and peptides with specific molecular binding activity for phage amplification. Specific peptides can be efficiently screened by leveraging the affinity between peptides displayed by M13 phages and target proteins or other biological macromolecules. Peptide sequences can be deduced from the associated nucleotide sequences (37-39). In the present study, mimic peptides were screened using PDT to investigate their inhibitory effect on DHBV functions. Mimic peptides have extensive application prospects due to their small size, low cytotoxicity, high stability and high membrane permeability.

The in vitro DHBV model is frequently used to perform pharmacodynamic analyses of HBV infection. Duck primary hepatocytes can be infected by DHBV 4 days following isolation; such a model can be used to investigate the effects of treatments on viral load, viral attacks and infection pathways of DHBV infection. Although DHBV and HBV have different genetic structures and functions, duck primary hepatocytes can be used to investigate the early steps of the viral replication process. Hence, results obtained from duck primary hepatocyte cultures could provide valuable and strong evidence to support studies of HBV (22).

To investigate the anti-viral activities of the mimic peptides in the present study, duck hepatocytes were treated directly with synthetic mimic peptides or transfected with plasmids expressing mimic peptides. The amino acid sequences of the mimic peptides were deduced from nucleotide sequences and synthesized. The synthetic mimic peptides were used to treat duck primary hepatocytes infected with DHBV, and the DHBV-DNA content of the nuclear fractions, cytoplasmic fractions and culture supernatants were determined at different time-points. In this study, normal cell morphology was found in each group, and the cell numbers of the experimental and control groups were similar.

The DHBV-DNA contents of the cell culture supernatants and cytoplasm fractions significantly decreased when the cells were treated with mimic peptides 2 or 7 , or these mimic peptides were intracellularly expressed. The DHBV-DNA content of the nuclear fractions of cells expressing mimic peptide 7 decreased the most.

The inconsistencies observed between the synthetic mimic peptide treatment and intracellular mimic peptide expression may be attributable to non-specific binding since this could not be completely ruled out by PDT. Mimic peptides with similar structures may have different biological functions due to their distinct functional sites. Accordingly, the present results demonstrated that mimic peptides 2 and 7 inhibited DHBV replication when applied directly, while the intracellular expression of mimic peptide 7 inhibited DHBV replication. These results indicate that mimic peptide 7 may have the potential to become an anti-HBV drug.

\section{Acknowledgements}

The present study was supported by the National Nature and Science Youth Fund of China (grant no. 81100286), the National Key Program for Infectious Diseases of China (grant no. 2013ZX10002001), the 12th Five-Year Significant New Drugs Creation Plan of the Ministry of Science and Technology of China (grant no. 2011ZX09302-003-03), and State Key Laboratory for Diagnosis and Treatment of Infectious Diseases (grant no. 2013013).

\section{References}

1. Rong Y, Song H, You S, Zhu B, Zang H, Zhao Y, Li Y, Wan Z, Liu H, Zhang A, et al: Association of Toll-like receptor 3 polymorphisms with chronic hepatitis B and hepatitis B-related acute-on-chronic liver failure. Inflammation 36: 413-418, 2013.

2. Tong MJ, Pan CQ, Hann HW, Kowdley KV, Han SH, Min AD and Leduc TS: The management of chronic hepatitis B in Asian Americans. Dig Dis Sci 56: 3143-3162, 2011.

3. Zhao Q, Peng L, Huang W, Li Q, Pei Y, Yuan P, Zheng L, Zhang Y, Deng J, Zhong C, et al: Rare inborn errors associated with chronic hepatitis B virus infection. Hepatology 56: 1661-1670, 2012

4. Meier A: Visualization and characterization of HBV-receptor interactions (unpublished $\mathrm{PhD}$ dissertation). Heidelberg University, 2010.

5. Köck J and Schlicht HJ: Analysis of the earliest steps of hepadnavirus replication: genome repair after infectious entry into hepatocytes does not depend on viral polymerase activity. J Virol 67: 4867-4874, 1993.

6. Drexler JF, Geipel A, König A, Corman VM, van Riel D, Leijten LM, Bremer CM, Rasche A, Cottontail VM, Maganga GD, et al: Bats carry pathogenic hepadnaviruses antigenically related to hepatitis B virus and capable of infecting human hepatocytes. Proc Natl Acad Sci USA 110: 16151-16156, 2013.

7. Lanford RE, Chavez D, Brasky KM, Burns RB 3rd, Rico-Hesse R: Isolation of a hepadnavirus from the woolly monkey, a New World primate. Proc Natl Acad Sci USA 95: 5757-5761, 1998.

8. Menne S and Cote PJ: The woodchuck as an animal model for pathogenesis and therapy of chronic hepatitis B virus infection. World J Gastroenterol 13: 104-124, 2007.

9. Schultz U, Grgacic E and Nassal M: Duck hepatitis B virus: An invaluable model system for HBV infection. Adv Virus Res 63: $1-70,2004$.

10. Nassal M, Leifer I, Wingert I, Dallmeier K, Prinz S and Vorreiter J: A structural model for duck hepatitis B virus core protein derived by extensive mutagenesis. J Virol 81: 13218-13229, 2007.

11. Murray SM, Freiman JS, Vickery K, Lim D, Cossart YE and Whiteley RK: Duck hepatitis B virus: A model to assess efficacy of disinfectants against hepadnavirus infectivity. Epidemiol Infect 106: 435-443, 1991.

12. Wong DK, Yuen MF, Yuan H, Sum SS, Hui CK, Hall J and Lai CL: Quantitation of covalently closed circular hepatitis B virus DNA in chronic hepatitis B patients. Hepatology 40: 727-737, 2004.

13. Levrero M, Pollicino T, Petersen J, Belloni L, Raimondo G, and Dandri M: Control of cccDNA function in hepatitis B virus infection. J Hepatol 51: 581-592, 2009.

14. Yang HC and Kao JH: Persistence of hepatitis B virus covalently closed circular DNA in hepatocytes: Molecular mechanisms and clinical significance. Emerg Microbes Infect 3: e64, 2014.

15. Li G, Fu L, Jiang J, Ping Y, Huang Y and Wang Y: SiRNA combinations mediate greater suppression of hepatitis B virus replication in mice. Cell Biochem Biophys 69: 641-647, 2014.

16. Qi FH, Wang ZX, Cai PP, Zhao L, Gao JJ, Kokudo N, Li AY, Han JQ and Tang W: Traditional Chinese medicine and related active compounds: A review of their role on hepatitis B virus infection. Drug Discov Ther 7: 212-224, 2013.

17. Qiu LP, Chen L and Chen KP: Antihepatitis B therapy: A review of current medications and novel small molecule inhibitors. Fundam Clin Pharmacol 28: 364-381, 2014. 
18. Zhou YB, Wang YF, Zhang Y, Zheng LY, Yang XA, Wang N, Jiang JH, Ma F, Yin DT, Sun CY and Wang QD: In vitro activity of cepharanthine hydrochloride against clinical wild-type and lamivudine-resistant hepatitis B virus isolates. Eur J Pharmacol 683: $10-15,2012$.

19. Nassal M: Hepatitis B viruses: Reverse transcription a different way. Virus Res 134: 235-249, 2008.

20. Tujios SR and Lee WM: Update in the management of chronic hepatitis B. Curr Opin Gastroenterol 29: 250-256, 2013.

21. Schacke M, Glück B, Wutzler P and Sauerbrei A: In vitro cultivation and cryopreservation of duck embryonic hepatocytes. J Virol Methods 157: 25-31, 2009.

22. Sauerbrei A, Schacke M, Schultz U, Egerer R, Merkle I, Glebe D, Gerlich W and Wutzler P: Alternative methods for validation of cell culture infection with duck hepatitis B virus. J Virol Methods 129: 178-185, 2005.

23. Wang Y, Li Y, Yang C, Hui L, Han Q, Ma L, Wang Q, Yang G and Liu Z: Development and application of a universal Taqman real-time PCR for quantitation of duck hepatitis B virus DNA. J Virol Methods 191: 41-47, 2013.

24. Mohamadkhani A, Jazii FR, Sayehmiri K, Jafari-Nejad S, Montaser-Kouhsari L, Poustchi H and Montazeri G: Plasma myeloperoxidase activity and apolipoprotein A-1 expression in chronic hepatitis B patients. Arch Iran Med 14: 254-258, 2011.

25. Zhang Z, Zhang JY, Wang LF and Wang FS: Immunopathogenesis and prognostic immune markers of chronic hepatitis $B$ virus infection. J Gastroenterol Hepatol 27: 223-230, 2012.

26. Zhong B, Huang MP, Yin GQ and Gao X: Effects of costimulation on intrahepatic immunopathogenesis in patients with chronic HBV infection. Inflamm Res 63: 217-229, 2014

27. Wang YX, Wen YM and Nassal M: Carbonyl J acid derivatives block protein priming of hepadnaviral $\mathrm{P}$ protein and DNA-dependent DNA synthesis activity of hepadnaviral nucleocapsids. J Virol 86: 10079-10092, 2012.

28. Funk A, Mhamdi M, Will H and Sirma H: Avian hepatitis B viruses: Molecular and cellular biology, phylogenesis and host tropism. World J Gastroenterol 13: 91-103, 2007.
29. Kumar A, Dwivedi M, Misra SP, Narang S, Tiwari BK and Pandey R: Clinical profile, genotype and management updates of hepatitis B virus. Indian J Virol 22: 1-10, 2011.

30. Guo H, Mao R, Block TM and Guo JT: Production and function of the cytoplasmic deproteinized relaxed circular DNA of hepadnaviruses. J Virol 84: 387-396, 2010.

31. Kock J, Rosler C, Zhang JJ, Blum HE, Nassal M and Thoma C: Generation of covalently closed circular DNA of hepatitis B viruses via intracellular recycling is regulated in a virus specific manner. PLoS Pathog 6: e1001082, 2010.

32. Campagna MR, Liu F, Mao R, Mills C, Cai D, Guo F, Zhao X, Ye H, Cuconati A, Guo H, et al: Sulfamoylbenzamide derivatives inhibit the assembly of hepatitis B virus nucleocapsids. J Virol 87: 6931-6942, 2013.

33. Cao F, Jones S, Li W, Cheng X, Hu Y, Hu J and Tavis JE: Sequences in the terminal protein and reverse transcriptase domains of the hepatitis $B$ virus polymerase contribute to RNA binding and encapsidation. J Viral Hepat 21: 882-893, 2014.

34. Fu L and Cheng YC: Role of additional mutations outside the YMDD motif of hepatitis B virus polymerase in L(-)SddC (3TC) resistance. Biochem Pharmacol 55: 1567-1572, 1998.

35. Liang J, Tang YF, Wu FS and Deng X: Entecavir versus lamivudine for the treatment of chronic hepatitis B: A systematic review. Pharmazie 67: 883-890, 2012.

36. Liu Q and Jia RY: Research on the gene structure of duck hepatitis B virus and its encoding proteins. Bing Du Xue Bao 28: 681-688, 2012 (In Chinese).

37. Finlay WJ, Bloom L and Cunningham O: Phage display: A powerful technology for the generation of high specificity affinity reagents from alternative immune sources. Methods Mol Biol 681: 87-101, 2011.

38. Jin HE, Farr R and Lee SW: Collagen mimetic peptide engineered M13 bacteriophage for collagen targeting and imaging in cancer. Biomaterials 35: 9236-9245, 2014.

39. Koduvayur SP, Gussin HA, Parthasarathy R, Hao Z, Kay BK and Pepperberg DR: Generation of recombinant antibodies to rat GABAA receptor subunits by affinity selection on synthetic peptides. PLoS One 9: e87964, 2014. 